\title{
Positive and negative contrast effects obtained following shifts in liquid sucrose reward in thirsty rats
}

\author{
MITRI E. SHANAB, JOHN FRANCE, and TED YOUNG \\ California State University, Fresno, California 93740
}

\begin{abstract}
In a repeated shifts experiment four independent groups of thirsty rats received the following treatments: LSLS, LLLS, SSLS, and SSSS, with each letter denoting the magnitude (large or small) of sucrose reward received in each of the four phases of the experiment. While no negative contrast effect (NCE) was obtained in Phase 2, a very reliable positive contrast effect (PCE) was found in Phase 3. Moreover, a significant NCE was obtained in Phase 4 . The results were explained in terms of the relative rather than absolute effects of reinforcement.
\end{abstract}

Crespi (1942) was probably the first investigator to popularize the phenomenon of incentive contrast. He reported obtaining both a positive $\mathrm{PCE}$ ) and a negative (NCE) contrast effect. Subjects shifted from small to larger rewards were observed to run at a faster rate than would be expected from a control group kept on large reward all the time (elation effect or PCE). Conversely, when subjects were shifted from large to a smaller reward, they undershot the level of the subjects receiving small reward all the time (depression effect or NCE). Attempts to replicate Crespi's findings of PCE have failed repeatedly. When appropriate controls for the ceiling effects were introduced, PCE was consistently obtained (Shanab, Birnbaum, \& Cavallaro, 1974) Recently, however, some studies have obtained PCE without such controls (cf. Weinstock, 1971).

Crespi's findings of NCE in the runway based on shifts in food reward have been successfully replicated in many laboratories (Dunham, 1968). However, when either magnitude or concentration of liquid sucrose (Goodrich, 1962; Homzie \& Ross, 1962; Ison \& Rosen, 1968; Rosen, 1966; Rosen \& Ison, 1965), or both magnitude and concentration of liquid sucrose were simultaneously downshifted (Barnes \& Tombaugh, 1973; Flaherty, Riley, \& Spear, 1973; Ison \& Rosen, 1968), no NCE was obtained. The dependent variable in the previous studies was response speed. It should be noted that a NCE was reported with liquid sucrose when the dependent variable was either the frequency of the licking response (Vogel, Mikulka, \& Spear, 1968), or the barpress response (Collier \& Marx, 1959; Weinstein, $1970 \mathrm{a}, \mathrm{b})$.

A closer examination of Crespi's design for positive contrast reveals that he used a double-shift in that his PCE subjects originally recieved large reward followed by a shift first to small reward and then back to large reward. Crespi (1942) reasoned that in order to obtain a

Reprint requests should be sent to Mitri E. Shanab, Psychology Department, California State University, Fresno, Fresno, California, 93740.
PCE the subject must first experience a frustratingly small reward before being shifted to large reward. Using food reward, Weinstock (1971) failed to replicate the double-shift PCE obtained by Crespi. However, several studies (Benefield, Oscos, \& Ehrenfreund, 1974; Calef, 1972; Shanab \& Ferrell, 1975) obtained significant PCE using food reward based on a double-shift procedure. Moreover, Shanab, Young, and France (1975), using sucrose reward, recently reported obtaining a positive contrast-like effect when subjects were shifted from small to large reward after having previously received large reward. Unfortunately, there was no control group that received large reward all the time. The present study was designed to accomplish at least two purposes. One purpose was to replicate under more appropriate control conditions the results of the latter study (viz. Shanab, Young, \& France, 1975) and hence extend the generality of the findings of the earlier food studies (Benefield et al., 1974; Crespi, 1942; Shanab \& Ferrell, 1975). A second purpose was to test a deduction made from the explanation of contrast effects offered by Benefield et al. (1974) based on Crespi's earlier theory of eagerness (1944). According to this view a PCE occurs if subjects have already experienced a frustratingly small reward before being shifted back to large reward. It should follow then that a NCE would occur when the organism has had commerce with a large reward before being given small reward again.

As noted earlier, although Crespi and many other investigators using food reward have obtained NCE based on a single-shift (Dunham, 1968), attempts to obtain NCE in the runway based on a simple shift from large sucrose to small sucrose reward have failed consistently (cf. Shanab, France, \& Young, 1975; Shanab, Young, \& France, 1975). It is conceivable that a NCE could be obtained with sucrose reward if a double-shift procedure is used, i.e., if subjects first receive small reward followed by large then small reward again. The prediction should hold for both magnitude and concentration of sucrose. It could be argued that such 


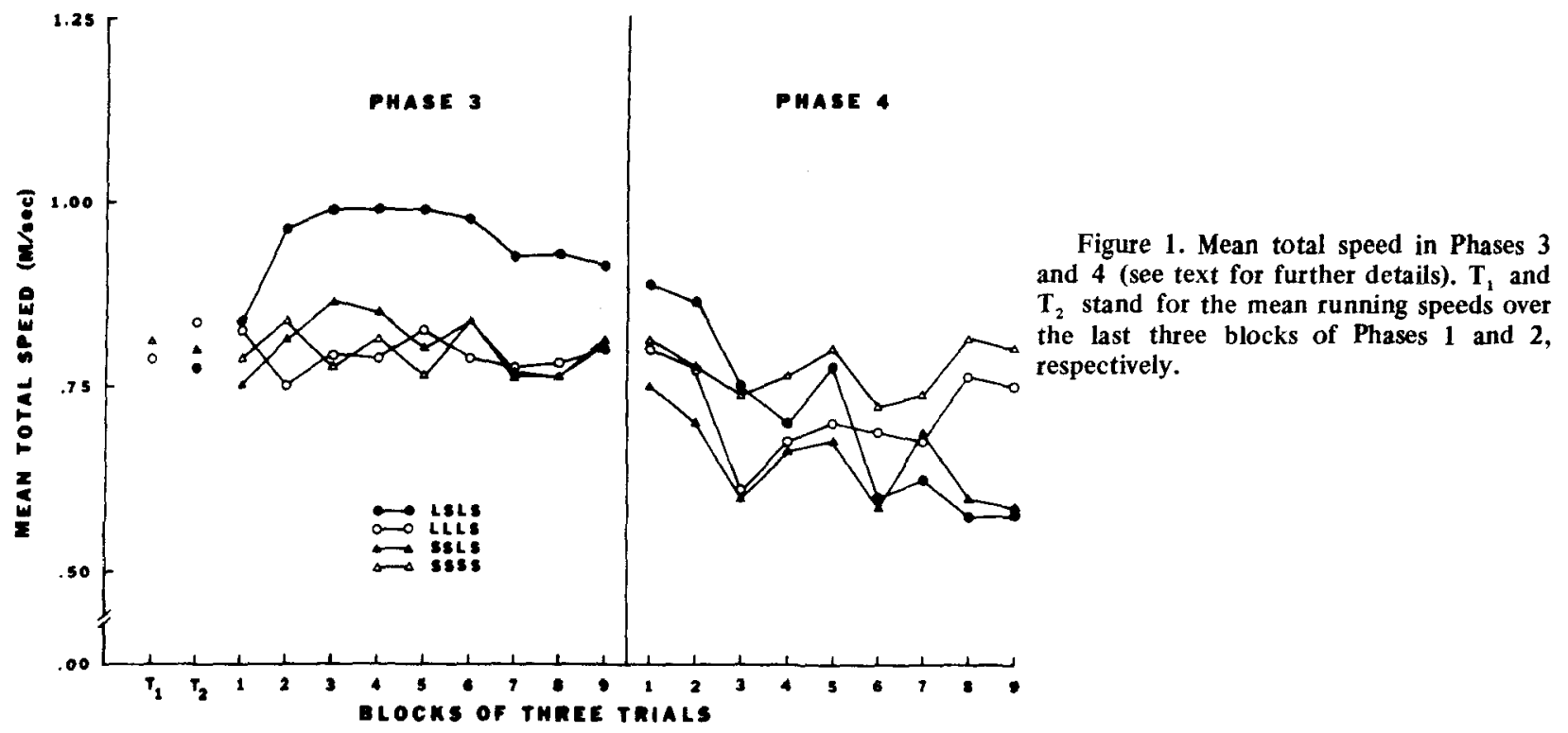

conditions also enhance the perceptual differences between the shifted magnitudes or concentrations of sucrose reward, thus allowing for the emergence of positive and negative contrast. Opposed to this relative interpretation of contrast is the absolute view (Capaldi \& Lynch, 1967) which predicts that repeated shifts dampen if not eliminate contrast effects, especially negative contrast effects.

\section{METHOD}

\section{Design}

The subjects were assigned to four random groups of 10 rats each. The groups differed in terms of reward magnitude, receiving either $1.75 \mathrm{cc}(\mathrm{L})$ or $.20 \mathrm{cc}(\mathrm{S})$ of an $8 \%$ sucrose solution. Reward magnitude was shifted across all four phases of the experiment, with each group receiving one of the following treatments: LLLS, LSLS, SSLS, and SSSS; each letter denotes the magnitude of reward received in each phase.

\section{Subjects}

The subjects were 40 naive male albino rats of the SpragueDawley strain, approximately 80 days old at the beginning of the experiment.

\section{Apparatus}

A standard Hunter runway, Model 385, was used. The runway was modified in two ways: First, the guillotine doors separating the start from the run and the run from the goal sections were converted from electrical to manual operation. Second, a black, self-sticking plastic coating covered the sides and ends of the runway from the outside. The top remained clear Plexiglas.

Four photocells were used to record start, run, and goal times. The first photocell was located $8 \mathrm{~cm}$ into the runway from the startdoor. The second photocell was located $25 \mathrm{~cm}$ beyond the first, while the third photocell was placed $100 \mathrm{~cm}$ beyond the second photocell. The distance between the third and the fourth photocell was $25 \mathrm{~cm}$; the fourth photocell was placed $8 \mathrm{~cm}$ into the goalbox. The photocells were connected to electric timers which measured time to the nearest onehundredth second.
The lighting was supplied by two $25 \cdot \mathrm{W}$ red light bulbs placed approximately $1.5 \mathrm{~m}$ over the runway.

A clear plastic furniture coaster was used as the reinforcer cup which was $3.2 \mathrm{~cm}$ in dia and $6.3 \mathrm{~mm}$ deep. The sucrose solution was placed in the reinforcer cup by means of a needleless hypodermic syringe which also served to measure the magnitude of the sucrose delivered. A slot was made in the far wall of the goalbox through which the reinforcer cup was inserted.

\section{Procedure}

Upon arrival from the supplier, the subjects were housed individually and given 4 weeks free feeding. During this time the subjects were weighed and handled daily. Two weeks prior to Phase 1 , the subjects were adapted to a $23 \frac{1 / 2}{\mathrm{~h}}$ water deprivation schedule, receiving $1 / 2 \mathrm{~h}$ free access to water in their home cages daily. Five days prior to Phase 1 , the subjects were semirandomly assigned to one of the four groups, with the only restriction being that the mean weights of each group be approximately equal. Four days prior to Phase 1 , all subjects received $2 \mathrm{~min}$ of free exploration in the unbaited runway with all equipment turned off and the guillotine doors open.

Three days prior to Phase 1 , the subjects were given a second day of exploration for 1 min while all equipment was turned on. The subject was placed in the startbox, which was raised as soon as the subject oriented toward it. On the following 2 days, operant levels were taken by measuring the time taken by each subject to traverse the entire runway on the first run. No reinforcement was given during the exploration trials.

On Day 1 of Phase 1 a single reinforced trial was given, followed by two trials on Day 2 and three trials per day thereafter. On each trial each subject was taken out of its home cage, brought to the adjoining experimental room, and then returned to the home cage upon completion of each trial. The subjects were run in squads of three with an ITI of approximately 3-5 min. During this phase, each subject received either $1.75 \mathrm{cc}(\mathrm{L})$ or $.20 \mathrm{cc}(\mathrm{S})$ of $8 \%$ sucrose reward. Throughout the experiment, the reinforcement consisted of commercial sugar and water mixed $24 \mathrm{~h}$ prior to use and stored at room temperature. The $8 \%$ solution was made by mixing 8 grams of sugar with $100 \mathrm{cc}$ of water. Each subject received $1 / 2 \mathrm{~h}$ access to water in its home cage at least $30 \mathrm{~min}$ after its last daily trial. Each subject received 36 trials in Phase 1. In Phase 2, half of the subjects receiving large $(1.75 \mathrm{cc})$ reward were shifted to small $(.20 \mathrm{cc})$ reward (Group LS), while the other half continued on 
the same large reward (Group LL). The other small group (Group SS) continued to receive the same small reward magnitude as before. Phase 2 lasted 27 trials. In Phase 3, subjects in both Groups LL and SS were shifted to large reward, giving rise to Groups LSL and SSL. The LL and SS subjects continued to receive the same reward magnitude as before (Groups LLL and SSS). The third phase lasted 27 trials also. In Phase 4, all subjects received small reward, resulting in the following groups: LSLS, LLLS, SSLS, and SSSS, making the latter a common control group. Phase 4 also lasted 27 trials.

\section{RESULTS}

Since all speed measures were essentially alike, only total speeds will be reported. An analysis of variance test with repeated measures over the last three blocks of Phase 1 yielded nonsignificant results for blocks and for the interaction of blocks with treatments, [both Fs $<11$, indicating that the performance of the two groups had stabilized by the end of Phase 1 . The treatments effect was also not significant $[F(1 / 38)<1]$. A similar test on the last three blooks of Phase 2 yielded almost identical results. Neither the blocks effect $[F(2 / 74)<1]$ nor the Blocks by Treatments interaction effect $[F(4 / 74)<1]$, was significant, indicating that all three groups reached a stable level by the end of Phase 2 . The treatments effect was not significant $[F(2 / 37)<1]$. There was no indication of a NCE throughout Phase 2.

As Figure 1 shows, the LSL group ran significantly faster in Phase 3 than the main control group (Group LLL), as well as the SSL group, thus displaying a positive contrast effect. To check this graphical analysis, a simple analysis of variance test was performed on mean speeds collapsed across Blocks 2-9 of Phase 3, yielding a significant treatments effect $[F(2 / 27)=3.67$, $\mathrm{p}<.05$ ]. It should be noted that Group SSS was excluded from the analysis, since it is not relevant to a test of PCE. Individual comparisons using the $t$-test revealed that Group LSL ran faster than either Group LLL $[\mathrm{t}(18)=2.62, \mathrm{p}<.05]$ or Group SSL, $[\mathrm{t}(18)=2.45, \mathrm{p}<.05]$. There was no significant difference between Groups LLL and SSL, $[\mathrm{t}(18)<1]$.

In Phase 4, as will be recalled, all subjects received small reward, with three groups having a mixed history of small and large reward while the fourth group received small reward all the time. Separate analyses of variance were performed on mean speeds over Blocks 3-9 and Blocks 6-9 of Phase 4, yielding very similar results. The treatments effect was significant $[F$ s $(3 / 36)=3.64$ and $8.54, p<.05$ and $p<.001]$ over Blocks $3-9$ and $6-9$, respectively. Since Group SSSS represents a common control group for the other three groups, a Dunnett's test was used to evaluate the apparent negative contrast effects depicted in Figure 1. The results showed that both the SSLS and the LSLS ran significantly slower than the SSSS subjects over Blocks 3-9, $[t=3.03, p<.01$, and $t=2.37, p<.05]$ respectively. Similar results were obtained for Blocks
$6-9$, [ts $=4.33$ and 3.92 , both ps $<.01]$ for the LSLS vs. SSSS and the SSLS vs. SSSS comparisons, respectively. There was no significant difference between Groups SSSS and LLLS [ts $=1.64$ and 1.37, both ps $>.05]$ for Blocks 3-9 and 6-9, respectively.

\section{DISCUSSION}

The results of this study provide probably the first successful demonstration in the runway of both PCE and NCE based on shifts in magnitude of liquid sucrose reward in thirsty rats. The finding of a PCE following a double or repeated shift procedure supports other food studies (Benefield et al., 1974; Calef, 1972; Shanab \& Ferrell, 1975) but is at variance with the study by Capaldi and Lynch (1967). The discrepancy could be attributed to the fact that Capaldi and Lynch used a rather long ITI $(24 \mathrm{~h})$ and short training trials (15 trials per phase). Moreover, in their final phase which is somewhat comparable to Phase 4 of the present study, no control group such as the present SSSS group was run. The present finding of PCE supports and extends that obtained in the study by Shanab, Young, and France (1975) in which liquid sucrose reward was also used.

The present results provide strong support to the relative interpretation of contrast (cf. Benefield et al., 1974; Crespi, 1944) that a shift from a frustratingly small reward to large reward is a sufficient condition for positive contrast. This was supported by the fact that only those subjects which had first received large reward followed by small reward then large reward again (Group LSL) showed a PCE. Those subjects which had no prior experience with large reward before the shift to large reward (Group SSL) did not show any PCE. Similarly, those subjects which had previous commerce with small reward (Groups LSLS and SSLS) showed a significant NCE, while those subjects which had no prior experience with small reward (Group LLLS) performed at the same level as the control subjects. According to Crespi (1944), PCE occurs whenever level of achievement exceeds level of expectation, while the opposite is true for NCE. Crespi assumed that the shift in reward conditions produced an additional drive, frustration or anger, which either augmented performance above control levels (PCE) or depressed performance below a control level (NCE). Helson (1964) proposed a similar explanation of contrast. According to Helson, a PCE takes place whenever the obtained reward exceeds that expected on the basis of a norm (adaptation level) already formed by the subject as a result of experience with past reward conditions. The obverse would account for NCE. Recently, Capaldi (1974) proposed a reinforcement-level hypothesis which is similar to both Crespi's eagerness hypothesis (1944) and Helson's adaptation-level hypothesis (1964). Capaldi (1974) suggested that PCE occurs if the expected reward is below the obtained reward, while NCE occurs if the 
expected is greater than the obtained reward. None of the preceding relative or contextual explanations of contrast provides an operational definition of expectancy, thus making it difficult to deduce specific hypotheses to disconfirm them. In any case, it seems that current accounts of shifts in reinforcement conditions are cast in contextual or relative, rather than absolute, terms. It should be noted here that besides Capaldi other associationists (viz. Amsel, 1958; Black, 1968; McHose, 1970) also provided contextual interpretations of contrast.

Although more empirical investigations of contrast effects under various conditions still need to be carried out, the present findings of positive and negative contrast effects based on shifts in sucrose reward, coupled with the recent findings of PCE based on shifts in food reward (Shanab et al., 1974) and the comparable findings of behavioral contrast (Freeman, 1971), not only contribute to the reliability of contrast but also provide a wider empirical base for future theorizing and integration of the existing facts.

\section{REFERENCES}

Amsel, A. The role of frustrative nonreward in noncontinuous reward situations. Psychological Bulletin, 1958, 55, 102*119.

Barnes, W., \& Tombaugh, T. N. Another failure to obtain negative incentive contrast following reductions in sucrose reward. Psychological Reports, 1973, 33, 801-802.

Benefield, R., Oscos, A., \& Ehrenfreund, D. Role of frustration in successive positive contrast. Journal of Comparative and Physiological Psychology, 1974, 86, 648-651.

Black, R. W. Shifts in magnitude of reward and contrast effects in instrumental and selective learning: A reinterpretation. Psychological Review, 1968, 75, 114-126.

Calef, R. S. The effect of large and small magnitude of intertrial reinforcement on successive contrast effects. Psychonomic Science, 1972, 29, 309-312.

Capaldi, E. J. Partial reward either following or preceding consistent reward: A case of reinforcement level. Journal of Experimental Psychology, 1974, 102, 954-962.

Capaldi, E. J., \& Lynch, D. Repeated shifts in reward magnitude Evidence in favor of an associational and absolute (noncontextual) interpretation. Journal of Experimental Psychology, 1967, 75, 226-235.

Collier, G., \& Marx, M. H. Changes in performance as a function of shifts in the magnitude of reinforcement. Journal of Experimental Psychology, 1959, 57, 305-309.

Crespi, L. P. Quantitative variation in incentive and performance in the white rat. American Journal of Psychology, 1942, 55, 467-517.
Crespi, L. P. Amount of reinforcement and level of performance. Psychological Review, 1944, 51, 341-357.

Dunham, P. J. Contrasted conditions of reinforcement: A selective critique. Psychological Bulletin, 1968, 69, 295-315.

Flaherty, C. F., Riley, E. P., \& Spear, N. E. Effects of sucrose concentration and goal units on running behavior in the rat. Learning and Motivation, 1973, 4, 163-175.

Freeman, B. J. Behavioral contrast: Reinforcement frequency or response suppression? Psychological Bulletin, 1971, 75, 347-356.

Goodrich, K. P. Supplementary report: Running speed as a function of sucrose concentration in a prior free drinking period. Psychological Reports, 1962, 11, 528-530.

Helson, H. Adaptation level theory. New York: Harper \& Row, 1964.

Homzie, M. J., \& Ross, L. E. Runway performance following a reduction in the concentration of a liquid reward. Journal of Comparative and Physiological Psychology, 1962, 55, 1029-1033.

Ison, J. R., \& Rosen, A. J. Extinction and reacquisition performance as a function of sucrose-solution rewards and numbers of acquisition trials. Psychological Reports, 1968, 22, 375-379.

McHose, J. H. Relative reinforcement effects: $S_{1} / S_{2}$ and $S_{1} / S_{1}$ paradigms in instrumental conditioning. Psychological Review, 1970, 77, 135-146.

Rosen, A. J. Incentive-shift performance as a function of magnitude and number of sucrose rewards. Journal of Comparative and Physiological Psychology, 1966, 62, $487-490$.

Rosen, A. J., \& Ison, J. R, Runway performance following changes in sucrose rewards. Psychonomic Science, 1965, 2 , 335-336.

Shanab, M. E., Birnbaum, D. W., \& Cavallaro, G. Positive contrast obtained in reacquisition following interpolation of nonreinforced or partially reinforced trials. Learning and Motivation, 1974, 5, 258-271.

Shanab, M. E., \& Ferrell, H. H. Transfer between downshift in reward magnitude and continuous delay of reward. Learning and Motivation, 1975, 6, 241-252.

Shanab, M. E., France, J., \& Young, T. Negative contrast effects obtained with downshifts in magnitude but not concentration of solid sucrose reward. Bulletin of the Psychonomic Society, $1975,5,429-432$

Shanab, M. E., Young, T. \& France, J. Negative contrast as a function of downshifts in magnitude of sucrose concentrations in thirsty rats. Bulletin of the Psychonomic Society, $1975,5,381-385$.

Vogel, J. R., Mikulka, P. J., \& Spear, N. E. Effect of interpolated extinction and level of training on the "depression effect." Journal of Experimental Psychology, 1966. 72, 51-60.

Weinstein, L. Negative incentive contrast with sucrose. Psychonomic Science, 1970a, 19, 13-14.

Weinstein, L. Negative incentive contrast effects with saccharine vs. sucrose and partial reinforcement. Psychonomic Science, $1970 \mathrm{~b}, 21,276-278$.

Weinstock, L. Preacquisition exploration of the runway in the determination of contrast effects in the rat. Joumal of Comparative and Physiological Psychology, 1971, 75. 107-115.

(Received for publication April 22, 1975. Accepted June 10, 1975.) 